\title{
Virus Infection of the Human Papilloma and Its Association with Colorectal Cancer
}

\author{
Victor Manuel Vargas Hernández*, Victor Manuel Vargas Aguilar \\ Gynecologist Oncologist, Gynecology Department of Hospital Juárez of México, Insurgentes Sur 605-1403, Colonia Nápoles, Mexico. \\ *Corresponding author: Víctor Manuel Vargas Hernández Gynecologist Oncologist, Gynecology Department of Hospital Juárez of México, \\ Insurgentes Sur 605-1403, Colonia Nápoles, Mexico.
}

Received date: January 25, 2020; Accepted date: January 31, 2020; published date: February 12, 2020

Citation: Victor Manuel Vargas Hernández, Víctor Manuel Vargas Aguilar (2020) Virus Infection Of The Human Papiloma And Its Association With Colorectal Cancer. J Clinical Research and Reports, 2(4); DOI:10.31579/2690-1919/024

Copyright: ( 2020 Victor Manuel Vargas Hernández. This is an open access article distributed under the Creative Commons Attribution License, which permits unrestricted use, distribution, and reproduction in any medium, provided the original work is properly cited.

\begin{abstract}
Colorectal cancer is the third most common cancer in men and women worldwide; its carcinogenesis is a complex multi-step process that involves environmental factors, lifestyle, genetic mutation and viral infections; Human papillomavirus (HPV) infection plays a crucial role in human carcinomas, mainly anogenital and oropharyngeal; HPV is a prognostic factor since it is associated with vascular invasion, ganglionic metastases and tumor size; HPV is reported to be present in 70\% of colorectal cancers and HPV-16 E6 / E7 oncoproteins are involved in carcinogenesis, including colorectal cancer; prevention with HPV vaccines can prevent some cancers including colorectal cancer. The link between HPV and colorectal cancer became evident, without distinction between the sexes, with similar values between HPV 16 and HPV 18. Studies are needed to investigate the relationship between HPV and colorectal cancer.
\end{abstract}

Keywords: colorectal cáncer; high-risk HPV; E5 and E6 / E7 oncoproteins; cancinogenesis; risk factors

\section{Background}

Colorectal cancer is common and represents 1.36 million new cases worldwide each year; They are characterized by marked propensity for local invasion and nodal metastases. Despite advances in diagnosis and treatment, mortality is high without changes in the last four decades. The average overall survival in the last five years has been described at around $55 \%$ for developed countries and $40 \%$ for emerging countries [1,2].

Colorectal carcinogenesis is a complex multi-step process that involves environmental, demographic and lifestyle factors, in addition to genetic alterations and viral infections. The highest incidence of colorectal cancer is observed in Western Europe, North America, Australia, as well as in some countries in the Middle East. It is relatively lower in sub-Saharan Africa, South America and Asia; although, it increases gradually due to the lifestyle and eating habits of western countries; Two thirds of patients will develop distant metastases during the course of their illness, which is the leading cause of death [3-5].

Human papillomavirus (HPV) have been established as etiologic agents of anogenital and oropharyngeal cancers, where $96 \%$ are positive for high-risk HPV (HPV-ar); persistent infection with HPV-ar is necessary but not sufficient for the development of cancers [6,7], including colorectal, $54 \%$ of colorectal cancer are positive for HPV-ar; accompanied by expression / overexpression of the Fascin, Id-1 and Pcadherin genes, the main regulators of cell invasion and metastasis; E5 and E6 / E7 oncoproteins of HPV-ar could cooperate together to promote the progression of carcinogenesis through the deregulation of several key controlling genes of the epithelial-mesenchymal transition event (EMT) [8]. Colorectal cancer is a health problem in which HPV-ar infection can play an important role in its development, as well as metastasis through EMT.
Colorectal cancer, along with lung and breast cancers, are one of the deadliest diseases in the world today, they are the third leading cause of death; 5 to $6 \%$ of people will develop colorectal cancer in their life. These malignancies are more common in Europe, with 432,000 new cases reported annually, and the second most common cause of cancer death in Europe. In general, it is the second leading cause of cancer-related mortality worldwide and the third most commonly diagnosed malignant disease. The prognosis of colorectal cancer has slowly but steadily improved over the last decades in many countries, 5-year survival has reached $65 \%$ in developed countries, such as Australia, Canada, the United States and several European countries, but has remained below $50 \%$ in low-income countries. Survival decreases with age and, at early ages, is slightly higher for women than for men; taking into account that the diagnostic stage is the most important prognostic factor [9-12].

Colorectal cancer is common in the elderly; $90 \%$ of new cases of colorectal cancers are diagnosed in people over 50 with the average age at the time of diagnosis is 69 years, and their incidence increases with age ${ }^{13}$, patients may present a variety of signs and symptoms; The most common are changes in bowel habits, changes in the caliber of stool, weight loss, abdominal pain, hematochezia or occult blood and anemia due to rectal bleeding or signs of intestinal obstruction or perforation. Most colorectal cancers develop slowly. Infections due to pathogens or viruses are among the risk factors for their development $[13,14]$

The risk factors (FR) are the colon polyp, such as tubular, tubulovellous, hairy adenoma, hyperplastic polyp, adenoma or sessile serrated polyp, and traditional serrated adenoma, some hamartomatous polyps are considered premalignant lesions. Among precancerous polyps, adenomatous and advanced adenomatous polyps that have a polyp size> $10 \mathrm{~mm}$, hair / tubulovellosal histological features, or have high grade dysplasia, have a higher prevalence and incidence in the elderly, with the 
potential to progress to invasive adenocarcinomas [14, 15], is associated with a larger size, hairy morphology, TP53 mutation and deletion of a region of chromosome $18 \mathrm{q}$.

Chromosomal instability can be demonstrated in late precursor adenomas. In this sequence, the APC mutation is a common early event, while serrated lesions commonly have a BRAF or KRAS mutation. Other RFs include diet and lifestyle (such as eating red meat, smoking, alcoholism, weight gain, etc.), old age. For the most part, it arises sporadically, few cases are associated with inherited syndromes such as familial adenomatous polyposis (FAP; $<1 \%$ of colorectal cancer) where they show germline mutations in an allele of the tumor suppressor gene of adenomatous polyposis (APC), MUTYH-associated polyposis (MAP; rare recessive condition, carrier estimated at $1 \%$ ) and hereditary colon cancer / Lynch syndrome without polyposis (LS / HNPCC; 2-4\% colorectal cancer) [6].

The most common cancer in the large intestine is well or moderately differentiated adenocarcinoma, secretes varying amounts of mucin and according to the classification of the World Health Organization (WHO), histopathological variants with mucinous adenocarcinoma, ring cells sealed, medullary, micropapillary, cribiform, adenoschistic, fusiform and undifferentiated cells. The immunohistochemical markers used for the diagnosis of colorectal adenocarcinoma are cytokeratin (CK) 20, CK7 and CDX2. The most common immunophenotype of colorectal adenocarcinoma is positivity for CK20 and negativity for CK7; They are divided into four grades. G1 are well differentiated tumors (usually adenocarcinomas) that have more than $95 \%$ glandular structures. In addition, G2 are designated as moderately differentiated tumors with 50 to $95 \%$ gland formation. G3 are poorly differentiated tumors with 5-50\% gland formation; while G4 are highly aggressive and undifferentiated tumors with less than $5 \%$ gland formation. Recently, WHO also suggests dividing them into categories of low grade (G1 and G2) and high grade (G3 and G4). The diagnosis of G3 and G4 is relatively consistent, but the differentiation between $\mathrm{G} 1$ and $\mathrm{G} 2$ is associated with a significant degree of variability among observers; It is characterized by a marked propensity for invasion and metastasis; $20 \%$ of newly diagnosed colorectal cancer have distant metastases mainly in the liver and lungs 2.1 to $18 \%$ and isolated lung metastases in $9-18 \%$ in rectal cancer; although distant metastases can be identified in other organs, including bone and brain $[6,17]$.

The risk of developing colorectal cancer for life is 5 and $6 \%$ in the general population of developed countries, hereditary forms have been well established; most are sporadic; lifestyle and environmental factors that contribute to its development. In recent decades, infections with Helicobacter pylori virus and Epstein Barr virus are possible causal factors of gastric cancer and the possible role of viral infections, such as HPV-ar infection and herpesvirus in colorectal carcinogenesis [6,18-24]. HPV-ar is the etiologic agent of cervical cancer, more than $96 \%$ are positive for HPV-ar, which is the most common STI in the world. HPVar infection is important for the development of premalignant lesions and / or progression to cancer; HPV-ar, has carcinogenic effects in other cancers [7,31] and HPV-ar, are present in 30\%, specifically genotypes HPV-16, 18, 31, 33 and 35, the presence and prevalence of HPV-ar, in colorectal cancer; varies geographically; but, they are present all over the world; HPV-ar infection alone is not enough to induce the neoplastic transformation of normal human epithelial cells [6,25-29].

HPVs are small double-stranded DNA viruses that generally infect the cutaneous and mucous epithelial tissues of the anogenital and oropharyngeal tract. The HPV DNA genome encodes eight open reading frames. It is divided into three functional parts: the early region $(\mathrm{E})$, the late region (L) and a long control region (CSF). The E region is important for replication, cell transformation and control of viral transcription, while the $\mathrm{L}$ region encodes the structural proteins (L1-L2) that participate in the assembly. CSF is necessary for the replication and transcription of viral DNA. The seven proteins of the E region are E1, E2, E3, E4, E5, E6 and E7. E1 is necessary for viral DNA replication, while E2 has a role in transcription and replication of viral genes. The function of E3 is not yet understood. On the other hand, the E4 protein interacts with the keratin cytoskeleton and intermediate filaments. In addition, it facilitates the assembly and release of viruses. E5 protein interacts with growth factor receptors and stimulates cell proliferation and inhibits apoptosis. E6 induces DNA synthesis, prevents cell differentiation and interacts with tumor suppressor proteins and repair factors, E7 induces cell proliferation and interacts with negative regulators of the cell cycle and tumor suppressor proteins. E5, E6 and E7 proteins act as oncogenes that are associated with carcinogenesis [25]. Of the 150 different viral genotypes, one third of these infect the epithelial cells of the anogenital tract. HPVs are classified as high or low risk. Infections with low-risk genotypes are generally self-limited and do not lead to malignancy, HPV-ar infections (HPV-16, 18, 31, 33, 35, 39, 45, 51, 52, 55, 56, 58, genotypes 59, 68, 73, 82 and 83) are associated with the development of cancers where $96 \%$ are positive for HPV-ar, mainly for cervical cancer [6,29-30].

The early oncoproteins of HPV-ar, E5, E6 and E7, increase cell disruption and lead to carcinogenesis [25], E5 oncoprotein interacts with the EGFR1 signaling pathways (MAP kinase and P13K-Akt) and proapoptotic proteins; It can play an important role in cell transformation and tumor formation, it is believed that E6 and E7 of the HPV-ar genotypes, such as HPV16, work together on the lesions caused by this virus, since the two proteins are expressed from the Bicistronic mRNA and are initiated from the early promoter virus (p97). These proteins have functions that stimulate cell cycle progression and both can be associated with cell cycle regulators. The E6 viral protein complements the role of E7 and prevents the induction of apoptosis in response to the unscheduled entry of the S7 phase mediated by E7. The E6 protein is also involved in the inactivation of p53-mediated growth suppression and / or apoptosis and is associated with other proapoptotic proteins, such as Bak and Bax, E6 stimulates cell proliferation independently of E7 through its C- domain. PDZ-ligand terminal. E6-PDZ binding is sufficient to mediate suprabasal cell proliferation and contribute to metastatic tumor development by disrupting normal cell adhesion, the E7 oncoprotein is involved with members of the $\mathrm{pRb}$ family of proteins. The binding of $\mathrm{E} 7 \mathrm{to} \mathrm{pRb}$ displaces E2F, regardless of the presence of external growth factors and leads to the expression of proteins necessary for DNA replication; The role of E6 / E7 oncoproteins in HPV-ar associated carcinogenesis, in vivo and together under the human K14 promoter, tumors develop, oncogenic properties of E5 in vivo, exhibited epidermal hyperplasia, aberrant differentiation of the epithelium and spontaneous tumors ; HPV-ar play an important role in the onset and / or progression of cancer, through its E5, E6 and E7 oncoproteins [6,25,31].

\section{High-risk HPV in colorectal cancers}

HPV-ar is the etiologic agent of cervical cancer, more than $96 \%$ are positive for HPV-ar, which is the most common STI in the world. HPVar infection is important for the development of premalignant lesions and / or progression to cancer; HPV-ar, has carcinogenic effects in other cancers [7,31] and HPV-ar, are present in 30\%, specifically genotypes HPV-16, 18, 31, 33 and 35, the presence and prevalence of HPV-ar, in colorectal cancer; varies geographically; but, they are present all over the world; HPV-ar infection alone is not enough to induce the neoplastic transformation of normal human epithelial cells; Infected cells must undergo additional genetic changes and / or coinfection with another 
oncovirus to achieve complete transformation and, consequently, tumor formation; the E6 / E7 oncoproteins of the HPV-16 genotype cooperates with the ErbB-2 receptor to induce cell transformation, accompanied by a relocalization of $\beta$-catenin from the membrane of the lower layer to the nucleus in the cells; Cyclin D1 is the objective of E6 / E7 / ErbB-2 cooperation through the conversion of the role of $\beta$-catenin from a cellcell adhesion molecule to a transcriptional regulator, type D cyclines (D1, D2 and D3) are essential for cell transformation induced by E6 / E7 / ErbB-2 cooperation in cells: the effect of the cooperation of E6 / E7 with ErbB-2, in normal and cancerous epithelial cells, occurs through the phosphorylation of $\beta$-catenin tyrosine through the activation of ProtoOncogenic Proteins (pp60) (c -src); pp60 kinase (c-Src), cooperation between HPV-ar E6 / E7 oncoproteins and other oncogenes could occur in colorectal carcinogenesis [6,29].

The E6 / E7 oncoproteins of HPV-16 induce cellular transformation into normal primary human colorectal "mesenchymal" cell lines, NCE1 and NCE5 cells, NCE1 and NCE5 cells expressing E6 / E7 oncoproteins form colonies, an important characteristic of cancer cells, to determine the role of HPV-ar infection in human cancer cells, the effect of E6 / E7 of HPV16 induces invasive and metastatic abilities in cell phones in vitro and in vivo [33]. This is complemented by the overexpression of Id-1, a member of the helix-loop-helix family of transcription factors that regulate cell invasion and metastasis, the E6 / E7 oncoproteins regulate the activity of the Id-1 promoter in human cancer cells, HPV-ar, play an important role in the progression of carcinomas through deregulation in Id-1, and these HPV-16 E7 / E7 oncoproteins would have a similar role in colorectal carcinogenesis.

HPV-ar infection, in colorectal carcinogenesis, is through the effect of HPV-16 E6 / E7 oncoproteins on normal colorectal mesenchymal cells, NCM1 and NCM5 along with HPV E6 / E7 oncoprotein expression. 16 stimulate cell proliferation and induce cell transformation and cell migration; by promoting a positive regulation of cyclin type $\mathrm{D}$, cyclin $\mathrm{E}$, and Id-1, and the expression / overexpression of Fascina, Id-1 and Pcadherin proteins, the main regulators of cell invasion and metastasis; HPV-ar infection could play an important role in the onset and progression of cancers, including colorectal cancers; but, more studies are needed on risk factors, such as lifestyle and sexual behavior; Molecular and cellular studies determine the role of E5 and E6 / E7 oncoproteins in colorectal cancer, E5 has been proposed to cooperate with E6 / E7 oncoproteins to facilitate cancer progression through EMT; E5 and E6 / E7 of HPV-ar, cooperate with other oncogenes and / or risk factors such as smoking or alcoholism to initiate it [6].

The cooperative E5 and E6 / E7 oncoproteins of HPV-ar and colorectal carcinogenesis can cooperate with other overexpressions of oncogenes that are related to lifestyle and / or environmental factors to induce cell transformation and, consequently, the formation of Tumors, E5 and E6 / E7 together improve the progression of colorectal cancer through the onset of the epithelial-mesenchymal transition (EMT) event. The prevention strategy for HPV infections and their related cancers, with HPV vaccines, vaccines made from virus-like particles (VLP) that contain inactive HPV L1 proteins, proteins from each HPV virus genotype and specific for each genotype [25,34], the quadrivalent Gardasil vaccine for protection against genotypes 6 and 11 of low-risk HPV, which cause genital warts, and rarely, non-genital warts and HPV-16 and 18. The quadrivalent vaccine will not protect against anogenital diseases other than HPV-6, 11, 16 and 18. genotypes In 2010, the quadrivalent vaccine for the prevention of colorectal cancer was approved. The effectiveness of prevention is $77.5 \%$, the bivalent Cervarix vaccine; for the prevention of HPV-16 and 18. Infections On December 10, 2014, the nonavalent vaccine 35 Gardasil-9 was approved; It was approved to be administered in three intramuscular doses to men aged 9 to 15 years and women aged 9 to 26 years. It is directed to HPV-16 (responsible for $50 \%$ of cervical carcinogenesis), HPV-18 (detected in $20 \%$ of $\mathrm{CaCu}$ ) and genotypes HPV$31,33,45,52$ and 58, responsible for $25 \%$ of cervical cancer; HPV-6 and 11 genotypes cause genital warts, they are also included in the nonavalent vaccine [36] in women aged 16 to 26 years, the efficacy is $97 \% 37$, it will have an important role in the prevention of HPV infections and their related cancers, including colorectal cancer and its metastases [38].

\section{Discussion}

Recent studies have shown that $15 \%$ of existing cancers are due to HPVar infection, which is commonly found in tumors, is an etiological factor (Aran et al., 2016), the presence of HPV in colorectal cancer, shows its potential As a cancer factor in this cancer [39-40], the frequency of HPV DNA was $6.22 \%$ for cases of colorectal cancer. In colorectal cancer, the frequency for HPV-51 and 56 genotypes was $15.5 \%$; for HPV-31 and 33 genotypes, it was $7.1 \%$, for [58] HPV-16 genotypes, 18. it was $10.1 \%$. In another report the prevalence of HPV was $42.2 \%$, of these HPV-16 was detected in $63.2 \%$ [41]. The distribution and frequency of HPV depends on the geographic area and demographic factors [42], where a prevalence of HPV and colorectal cancer was $74 \%$ and $44 \%$, respectively.

The prevalence of HPV in colorectal cancer is varied in different parts of the world, indicating its dependence on culture, geographic location, religion and diet; HPV was detected in $32 \%$ of normal tissues and $81.2 \%$ of cancerous tissues, only HPV-16, 18, 6, 11 and 33 were detected, HPV was detected in (44\%), the prevalence of HPV in colorectal cancer it was $37.5 \%$ and $35 \%$, with HPV-18 in 32\% and HPV-16 in 18\% there is a link between colorectal cancer and HPV because of its prevalence $(51.8 \%)$, especially for HPV-16 and 18, due to late diagnosis, since confirmation of the disease is more frequent in stage III. Another factor that was observed is the lack of evidence in gender differences with respect to the prevalence of colorectal cancer due to HPV, since both sexes presented similar values $[43,44]$.

The location where HPV predominates is the anogenital area are associated with chronic infections, preceded by precursor lesions, with predilection for the glandular squamous cell transition zone, since both have common biological characteristics, including histopathological aspects, samples of patients diagnosed with colorectal carcinomas HPV has tropism through glandular epithelial cells and is the cause of infections of the skin and mucous membranes, taking into account the known molecular mechanisms of these individual viruses, there is a possibility that they alter the mechanisms cell cycle control, inhibit apoptosis, cause chromosomal instability and promote colorectal oncogenesis 3,8,9,13,20,23,31,33, although the number of copies of HPV DNA may be low, viral HPV plays an active role in the pathogenesis of colorectal carcinoma, showing a higher prevalence of V PH-16, followed by HPV-18, it is possible that the viral cause favors genetic instability and contributes to carcinogenesis [44].

The accumulation of genetic alterations can lead to the development of cancer, due to the progression of premalignant to malignant they did not find a correlation between staging and cell differentiation with the presence of HPV-16, HPV infection can be FR for the increase of the prevalence of colorectal cancer [45-48].

HPV has been detected in colorectal cancer, the role of HPV in colorectal carcinogenesis has not been elucidated and remains controversial, the high incidence of cancers associated with HPV [7.49-50] with the high mortality rate from colorectal cancer. 
A high prevalence of HPV infection (42.2\%) was detected, with (2.8\%) it was positive for a non-HPV-16 genotype. The prevalence of HPV infections in colorectal cancers has been reported in 44, 51, 53 to 69\%; and $33 \%$ of non-neoplastic colorectal tissues; although, it has been suggested that HPV infection is not FR for colorectal cancer [5,44-50].

HPV-16 is the most common high-risk genotype and is highly prevalent in anogenital and head and neck cancers and is reported in 16 to $94 \%$ of colorectal cancer; These discrepancies regarding the detection of HPV-16 in colorectal cancer are attributed to methodological differences in the studies. Additional differences in the detection of HPV in colorectal cancer have been associated with regional variations in the prevalence of HPV infection, which are influenced by racial / ethnic and geographic backgrounds; where, HPV-18 is most frequently detected in colorectal cancer in Asia and Europe. HPV was detected in $21.05 \%$ of proximal tumors, $42.11 \%$ of distal and $36.84 \%$ in rectum. The wide anatomical distribution of HPV infections in tumor tissue with colorectal cancer implies that HPV infection in colorectal cancer is not the result of retrograde viral transmission from the anogenital area and the possibility of hematogenous dissemination is not ruled out. There is evidence of HPV infections in newborns and virgins, which supports that the transmission of HPV through other non-sexual routes may exist [7,51-56]; Since HPV infection is an STI, sexual behavior should be investigated.

The integration of the virus into the host genome is a critical step in carcinogenesis; through the expression of viral oncoproteins E6 and E7. The high percentage of HPV-16 genome integration in the host genome supports the possibility that HPV may have a role in colorectal carcinogenesis. Despite the high prevalence of infection in colorectal tumors with a high-risk type of HPV (HPV-16) and evidence of viral genome integration, HPV infections should be evaluated and whether the E6 and E7 oncoproteins are express and contribute and / or have a causal role in colorectal carcinogenesis [57]; however, it is not enough in the literature to conclude that HPV is a causative agent of colorectal cancer [55-56] as in $\mathrm{CaCu}$ [5,25-32]; HPV has also been detected in precursor lesions of colorectal cancer [6,57-63].

The high prevalence of HPV infection, mainly of HPV-16 (a high-risk type) and the integration of the HPV-16 genome into colorectal tumor tissue, requires further studies to establish a causal association between HPV and colorectal cancer [63-64].

\section{Conclusion}

The results provide evidence of an association between HPV and colorectal cancer risk. Its presence suggests potential cancer factor in this cancer. More studies are needed to investigate the relationship between HPV and colorectal cancer, when it was diagnosed was HPV positive $51.8 \%$, the majority related to HPV-16 and 18, HPV infection, is the most common STI in Worldwide and is related to colorectal cancer, it has become an important method in early diagnosis for prevention.

There is substantial evidence that HPV-ar, are present in colorectal cancer, through their E5 and E6 / E7 oncoproteins, could play an important role in the onset and progression of cancer, further studies are required to determine the function of oncogenes E5 and E6 / E7 in normal colorectal cells and human cancer cells, to identify the exact role of these oncoproteins and their possible cooperation in colorectal carcinogenesis. The prevention and elimination of known RF, especially unprotected sexual activity, sedentary lifestyle, smoking, alcoholism, high consumption of red meat and HPV-ar infections could decrease its development, prevention with available vaccines could prevent it, regardless of gender.

\section{References}

1. Ferlay J, Soerjomataram I, Dikshit R, Eser S, Mathers C, et al (2015) Cancer incidence and mortality worldwide: sources, methods and major patterns in GLOBOCAN 2012. International Journal of Cancer. 136:E359-86.

2. Rose J, Augestad KM, Cooper GS (2014) Colorectal cancer surveillance: what's new and what's next. World Journal of Gastroenterology. 20:1887-1897

3. Beg S, Siraj AK, Prabhakaran S, Bu R, Al-Rasheed M, et al (2015) Molecular markers and pathway analysis of colorectal carcinoma in the Middle East. Cancer. 2015; 121:3799-3808.

4. Tezcan G, Tunca B Ak S, Cecener G, Egeli U (2016) Molecular approach to genetic and epigenetic pathogenesis of early onset colorectal cancer. World Journal of Gastrointestinal Oncology. 8:83-98.

5. Mattar RE, Al-Alem F, Simoneau E, Hassanain M (2016) Preoperative selection of patients with colorectal cancer liver metastasis for hepatic resection. World Journal of Gastroenterology. 22:567-581.

6. Ala-Eddin Al Moustafa, Noor Al-Antary and Amber Yasmeen (2016) High-Risk Human Papillomavirus and Colorectal. Carcinogenesis. In Rajamanickam Rajkumar Ed, HumanPapillomavirus Research in a Global Perspective Edit. INTECH 2016, pp. 170-187.

7. Vargas-Hernández VM, Garcia-Jimenez E, Chávez Zúñiga MI, Tovar-Rodriguez JM, Moreno-Eutimio MA (2013) Infección oculta por virus del papiloma humano en la infancia y riesgo de carcinogenesis Rev Enf Tract Gen Inf. 7(1)ene-dic:18-25

8. Al Moustafa AE (2015) E5 and E6/E7 of high-risk HPVs cooperate to enhance cancer progression through EMT initiation. Cell Adh Migr. Sep-Oct; 9(5): 392-393.

9. Matuchansky C (2017) Colorectal cancer: Some present aspects of its epidemiology, prevention and screening. Press Med. 46:141144.

10. Marley AR, Nan H (2016) Epidemiology of colorectal cancer. Int J Mol Epidemiol Genet. 7:105-114.

11. Day LW, Velayos F (2015) Colorectal cancer screening and surveillance in the elderly: updates and controversies. Gut and Liver. 9:143-151.

12. Marin-Gabriel JC, Fernandez-Esparrach G, Diaz-Tasende J, Herreros de Tejada A (2016) Colorectal endoscopic submucosal dissection from a Western perspective: today's promises and future challenges. World Journal of Gastrointestinal Endoscopy. 8:40-55.

13. Ballester V, Rashtak S, Boardman L (2016) Clinical and molecular features of young-onset colorectal cancer. World Journal of Gastroenterology. 22:1736-1744.

14. Christensen TD, Palshof JA, Larsen FO (2017) Risk factors for brain metastases in patients with metastatic colorectal cancer. Acta Oncol.56:639-645

15. Leila Z, Arabzadeh SA, Afshar RM (2016) Detection of EpsteinBarr virus and cytomegalovirus in gastric cancers in Kerman, Iran. Asian Pac J Cancer Prev.17:2423-2428.

16. Vargas-Hernández VM, Acosta-Altamirano G (2012) Prevención primaria del cáncer cervicouterino Cir Cir ;80:291-300

17. Bai Z, Wang J, Wang $\mathrm{T}$ (2017) Clinicopathologic parameters associated with postoperative complications and risk factors for tumor recurrence and mortality after tumor resection of patients with colorectal cancer. Clin Transl Oncol. 18:1-17.

18. Al-Azri M, Al-Kindi J, Al-Harthi T (2017) Awareness of stomach and colorectal cancer risk factors, symptoms and time taken to seek medical help among public attending primary pare setting in Muscat governorate. Oman J Cancer Educ. 11:1-12. 
19. Aran V, Victorino AP, Thuler LC (2016) Colorectal cancer: epidemiology, disease mechanisms and interventions to reduce onset and mortality. Clin Colorectal Cancer. 15:195-203.

20. Bernabe-Dones RD, Gonzalez-Pons M, Villar-Prados A (2016) High prevalence of human papillomavirus in colorectal cancer in hispanics: A case-controlstudy. Gastroenterol Res Pract.

21. Karbalaie Niya MH, Safarnezhad Tameshkel F, Panahi M (2017) Human papillomavirus investigation in head and neck squamous cell carcinoma:initial report from the low risk HPV types associations. Asian Pac J Cancer Prev.18:2573-2579.

22. Leila Z, Arabzadeh SA, Afshar RM (2016) Detection of EpsteinBarr virus and cytomegalovirus in gastric cancers in Kerman, Iran. Asian Pac J Cancer Prev. 17:2423-2428.

23. Chen H, Chen XZ, Waterboer T, Castro FA, Brenner H (2015) Viral infections and colorectal cancer: a systematic review of epidemiological studies. International Journal of Cancer. 137:12-24.

24. Aykan NF (2015) Red Meat and Colorectal Cancer. Oncol Rev. 2015 Dec 28;9(1):288. doi: 10.4081/oncol.2015.288. eCollection.

25. Vargas Hernández VM, Virus del papiloma humano. Aspectos epidemiológicos, carcinogénicos, diagnósticos y terapéuticos Ginecol Obstet Mex 1996;64;sept:411-417.

26. Colón-López V, Ortiz AP, Del Toro-Mejías L, Clatts MC, Palefsky JM (2014) Epidemiology of Anal HPV Infection in High-Risk Men Attending a Sexually Transmitted Infection Clinic in Puerto Rico. PLoS ONE 9(1): e83209.

27. Ortiz A. P., Unger E. R., Muñoz C., et al. Cross-sectional study of HPV-16 infection in a population-based subsample of Hispanic adults. BMJ Open. 2014; 4(2): e004203. doi: 10.1136/bmjopen2013-004203

28. Liu B., Taioli E. Associations between human papillomavirus and history of cancer among U.S. adults in the National Health and Nutrition Examination Survey (2003-2010) British Journal of Cancer. 2014;111(7):1448-1453.

29. Raul D. Bernabe-Dones, Maria Gonzalez-Pons, Alejandro VillarPrados, Mercedes Lacourt-Ventura, Heriberto Rodríguez-Arroyo, Sharon Fonseca-Williams, Francisco E. Velazquez, Yaritza DiazAlgorri, Sofia M. Lopez-Diaz, Nayra Rodríguez, Yasuhiro Yamamura, Marcia Cruz-Correa. High Prevalence of Human Papillomavirus in Colorectal Cancer in Hispanics: A Case-Control Study. Gastroenterol Res Pract. 2016; 2016: 7896716.

30. Chen H, Chen XZ, Waterboer T, Castro FA, Brenner H. Viral infections and colorectal cancer: a systematic review of epidemiological studies. International Journal of Cancer. 2015;137:12-24.

31. Bruni L, Albero G, Serrano B, Mena M, Gómez D, Muñoz J, Bosch FX, de Sanjosé S. ICO/IARC Information Centre on HPV and Cancer (HPV Information Centre). Human Papillomavirus and Related Diseases in the World. Summary Report 17 June 2019.

32. Vargas-Hernández VM, López-Velázquez JL, Cruz-Martínez J, Romero-Hernández S. Avances recientes en virus del papiloma humano Rev Enf Trac Gen Inf. ene-dic 2017;10(1-4):28-38.

33. Vargas Hernández VM, Gómez Pedroso Rea J, Mainero Ratchelous F, Cantú de León D. Virus del papiloma humano en patología mamaria En Virus del Papiloma Humano. 1a. Edición, 2017 Ed. Alfil 2017.

34. Handler MZ, Handler NS, Majewski S, Schwartz RA. Human papillomavirus vaccine trials and tribulations: Clinical perspectives. Journal of the American Academy of Dermatology. 2015;73:74356 ; quiz $57-8$

35. Vargas-Hernandez VM. Vacuna nonavalente Rev Enf Trac Gen Inf. 2016 ene-ago;9(1):4-5.

36. Hariri S, Unger ER, Schafer S, Niccolai LM, Park IU, et al. HPV type attribution in highgrade cervical lesions: assessing the potential benefits of vaccines in a population-based evaluation in the United States. Cancer Epidemiology, Biomarkers \& Prevention: A Publication of the American Association for Cancer Research, Cosponsored by the American Society of Preventive Oncology. 2015;24:393-9.

37. Vorno T, Lutsar K, Uuskula A, et al. Cost-effectiveness of HPV vaccination in the context of high cervical cancer incidence and low screening coverage. Vaccine. 2017; 35:6329-35.

38. Aran V, Victorino AP, Thuler LC, Ferreira CG. Colorectal Cancer: Epidemiology, Disease Mechanisms and Interventions to Reduce Onset and Mortality. Clin Colorectal Cancer. 2016 Sep;15(3):195203.

39. Reza Malekpour Afshar, Zeinab Deldar, Hamid Reza Mollaei, Seyed Alimohammad Arabzadeh, Maryam Iranpour. Evaluation of HPV DNA positivity in colorectal cancer patients in Kerman, Southeast IranAsian Pac J Cancer Prev. 2018; 19(1): 193 198.

40. Baandrup L, Thomsen LT, Olesen TB, Andersen KK, Norrild B, Kjaer SK. The prevalence of human papillomavirus in colorectal adenomas and adenocarcinomas: a systematic review and metaanalysis. Eur J Cancer. 2014 May;50(8):1446-61.

41. Bernabe-Dones RD, Gonzalez-Pons M, Villar-Prados A, LacourtVentura M, Rodríguez-Arroyo H, Fonseca-Williams S, Velazquez FE, Diaz-Algorri Y, Lopez-Diaz SM, Rodríguez N, Yamamura Y, Cruz-Correa M. High Prevalence of Human Papillomavirus in Colorectal Cancer in Hispanics: A Case-Control Study. Gastroenterol Res Pract. 2016;2016:7896716.

42. Jiafen $\mathrm{Hu}$, Nancy M. Cladel, Lynn R. Budgeon, Karla K. Balogh,Neil D. Christensen. The Mouse Papillomavirus Infection Model. Viruses. 2017 Sep; 9(9): 246

43. Marina K. Ibragimova, Matvey M. Tsyganov, Nicolay V. Litviakov. Human papillomavirus and colorectal cancer. Medical Oncology (2018) 35:140.

44. Zhang XH, Wang W, Wang YQ, Jia DF, Zhu L. Human papillomavirus infection and colorectal cancer in the Chinese population: a meta-analysis. Colorectal Dis. 2018 Nov;20(11):961969.

45. Malekpour Afshar R, Deldar Z, Mollaei HR, Arabzadeh SA, Iranpour M. Evaluation of HPV DNA positivity in colorectal cancer patients in Kerman Southeast Iran. Asian Pacific Journal of Cancer Prevention : Apjcp, 26 Jan 2018, 19(1):193-198.

46. Colón-López V., Ortiz A. P., Del Toro-Mejías L., Clatts M. C., Palefsky J. M. Epidemiology of anal HPV infection in high-risk men attending a sexually transmitted infection clinic in Puerto Rico. PLoS One. 2014 Jan 6;9(1):e83209.

47. A P Ortiz, E R Unger, C Muñoz, G Panicker, G Tortolero-Luna, M Soto-Salgado, Y Otero, E Suárez, C M Pérez. Cross-sectional study of HPV-16 infection in a population-based subsample of Hispanic adults. BMJ Open. 2014; 4(2): e004203.

48. Liu B., Taioli E. Associations between human papillomavirus and history of cancer among U.S. adults in the National Health and Nutrition Examination Survey (2003-2010) British Journal of Cancer. 2014;111(7):1448-1453

49. Thaisa Pelizzer, Caroline Pieta Dias, Julia PoetaI, Tânia TorrianiI, Cristian Roncada. Colorectal cancer prevalence linked to human papillomavirus: a systematic review with meta-analysis Rev. Bras. Epidemiol. vol.19 no.4 São Paulo Oct./Dec. 2016.

50. Mendez K., Romaguera J., Ortiz A. P., López M., Steinau M., Unger E. R. Urine-based human papillomavirus DNA testing as a screening tool for cervical cancer in high-risk women. Int J Gynaecol Obstet. 2014 Feb;124(2):151-5.

51. Cladel NM, Jiang P, Li JJ, Peng X, Cooper TK, Majerciak V, Balogh KK, Meyer TJ, Brendle SA, Budgeon LR, Shearer DA, Munden R, 
Cam M, Vallur R, Christensen ND, Zheng ZM, Hu J. Papillomavirus can be transmitted through the blood and produce infections in blood recipients: Evidence from two animal models. Emerg Microbes Infect. 2019;8(1):1108-1121.

52. Estêvão D1, Costa NR2, Gil da Costa RM3, Medeiros R4Hallmarks of HPV carcinogenesis: The role of E6, E7 and E5 oncoproteins in cellular malignancy. Biochim Biophys Acta Gene Regul Mech. 2019 Feb;1862(2):153-162

53. Maria Raffaella Ambrosio, Remo Vernillo, Sabrina De Carolis, Antonietta Carducci, Lucia Mundo, Alessandro Ginori, Bruno Jim Rocca, Valerio Nardone, Alessandra Lucenti Fei, Tommaso Carfagno, Stefano Lazzi, Monica Cricca, and Piero Tosi. Putative Role of Circulating Human Papillomavirus DNA in the Development of Primary Squamous Cell Carcinoma of the Middle Rectum: A Case Report. Front. Oncol., 21 February 2019.

54. Habibollah Mirzaei, Hossein Goudarzi, Gita Eslami, and Ebrahim Faghihloo, "Role of viruses in gastrointestinal cancer," J Cellular Physiology, 2018;233(5):4000-4014.

55. Roesch-Dietlen F, Cano-Contreras AD, Sánchez-Maza YJ, Espinosa-González JM, Vázquez-Prieto MÁ, Valdés-de la O EJ, Díaz-Roesch F, Carrasco-Arroniz MÁ, Cruz-Palacios A, GrubePagola P, Sumoza-Toledo A, Vivanco-Cid H, Mellado-Sánchez G, Meixueiro-Daza A, Silva-Cañetas CS, Carrillo-Toledo MG, Lagunes-Torres R, Amieva-Balmori M, Gómez-Castaño PC, ReyesHuerta JU, Remes-Troche JM. Frequency of human papillomavirus infection in patients with gastrointestinal cancer. Rev Gastroenterol Mex. 2018 Jul - Sep;83(3):253-258.

56. Reza Malekpour Afshar, Zeinab Deldar, Hamid Reza Mollaei, Seyed Alimohammad Arabzadeh, Maryam Iranpour. Evaluation of HPV DNA positivity in colorectal cancer patients in Kerman, Southeast Iran. Asian Pac J Cancer Prev. 2018; 19(1): 193-198.
57. Zhang XH, Wang W, Wang YQ, Jia DF, Zhu L. Human papillomavirus infection and colorectal cancer in the Chinese population: a meta-analysis. Colorectal Dis. 2018 Nov;20(11):961969.

58. Damin D.C., Caetano M.B., Rosito M.A., Schwartsmann G., Damin A.S., Frazzon A.P., Ruppenthal R.D., Alexandre C.O. Evidence for an association of human papillomavirus infection and colorectal cancer. Eur. J. Surg. Oncol. 2007;33:569-574

59. Damin DC, Ziegelmann PK, Damin AP: Human papillomavirus infection and colorectal cancer risk: A meta-analysis. Colorectal Dis. 2013 Aug;15(8):e420-8.

60. M.K. Ibragimova, M.M. Tsyganov, N.V. Litviakov. Human papillomavirus and colorectal cancer. Med. Oncol. 5;35 (2018), pp: 140.

61. Z.Q .Sun, H.J. Wang, Z.L. Zhao, Q.S. Wang, C.W. Fan, F. Fang. Significance of HPV infection and genic mutation of APC and K-ras in patients with rectal cancer. Asian Pac J Cancer Prev. 2013;14(1):121-6

62. M. Snietura, D. Waniczek, E. Nowakowska-Zajdel, W. Piglowski, A. Kopec, M. MucWierzgon. Does human papilloma virus participate in colorectal carcinogenesis. J. Biol. Regul. Homeost. Agents. 26 (2012) pp: 757-762

63. A. Jarzyński, P, Zając R. Żebrowski, A. Boguszewska, M. PolzDacewicz. Occurrence of BK Virus and Human Papilloma Virus in colorectal cancer. Ann Agric Environ Med. 2017 Sep 21;24(3):440445. doi: 10.26444/aaem/74648.

64. Tan-Hsia Chen, Chi-Chou Huang, Kun-Tu Yeh, Shu-Hau Chang, Shih-Wen Chang, Wen-Wei Sung, Ya-Wen Cheng, Huei Lee. THuman papilloma virus 16 E6 oncoprotein associated with p53 inactivation in colorectal cancer. World J Gastroenterol 2012 August 14; 18(30): 4051-4058.

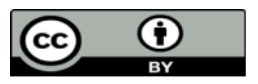

This work is licensed under Creative Commons Attribution 4.0 License

To Submit Your Article Click Here: Submit Manuscript

DOI: $10.31579 / 2690-1919 / 024$
Ready to submit your research? Choose Auctores and benefit from:

* fast, convenient online submission

* rigorous peer review by experienced research in your field

* rapid publication on acceptance

* authors retain copyrights

* unique DOI for all articles

* immediate, unrestricted online access

At Auctores, research is always in progress.

Learn more www.auctoresonline.org/journals/journal-of-clinical-researchand-reports 